\title{
An EAP Program and Students' Success at a Canadian University
}

\section{Karin Keefe E Ling Shi}

Many universities have instituted intensive English for Academic Purposes $(E A P)$ programs to support international students. This qualitative study used interviews to gain insights into the experiences of 8 non-native English speaking (NNES) students who completed an EAP program before they enrolled in disciplinary courses at a Canadian university. We followed and interviewed these students as they studied in the EAP program and then moved through the first term of university to identify how the EAP program prepared them for disciplinary courses. Results of the study illustrate that students' responses to the EAP program were mostly positive; all 8 students reported improvements and increased confidence in speaking and writing as they embarked on university classes. However, the participants reported challenges in their first term of university, including difficulty in understanding lectures, completing more complex writing tasks, adjusting to new expectations, and seeking social or peer support. The participants reported that all these challenges would have been greater had they not taken the EAP courses. Recommendations based on the findings are discussed.

Plusieurs universités ont établi des programmes intensifs d'anglais académique pour appuyer les étudiants internationaux. Cette étude qualitative s'est basée sur des entrevues pour obtenir un aperçu des expériences de 8 étudiants n'ayant pas l'anglais comme langue maternelle qui ont complété un programme d'anglais académique avant de s'inscrire à des cours liés à une discipline académique dans une université canadienne. Nous avons suivi ces étudiants et les avons interviewés pendant qu'ils suivaient le programme d'anglais académique et ensuite lors de leur premier semestre d'université pour identifier dans quelle mesure le programme d'anglais académique les avait préparés pour les cours réguliers. Les résultats révèlent que les étudiants ont réagi de façon surtout positive au programme d'anglais académique; tous les 8 étudiants ont signalé des améliorations et une confiance accrue face à l'anglais oral et écrit quand ils avaient commencé leurs cours universitaires. Toutefois, les participants ont évoqué des défis pendant leur premier semestre à l'université, y compris de la difficulté liée à la compréhension des cours, les tâches écrites plus complexes, l'ajustement aux nouvelles attentes et la recherche d'appui social ou des pairs. Les participants ont déclaré que ces défis auraient été encore plus importants sans les cours d'anglais acadé- 
mique qu'ils avaient suivis. Nous discutons de recommandations découlant des résultats.

KEYWORDS: EAP, international students, English language proficiency, undergraduate study, academic acculturation

In an ever-growing global economy, more and more students are crossing borders to study at English-medium universities in Canada and other western countries. In response to the large numbers of applicants who have the academic prerequisites but lack the English language proficiency requirements, many universities have instituted intensive English for Academic Purposes (EAP) programs. These programs may be pre-entrance pathway programs that serve as proof of language proficiency. One such example is the EAP program offered at the English Language Centre at the Canadian university that is the focus of this study. This EAP program offers intensive language programs of varying lengths throughout the year for both graduates and undergraduates with conditional admission to the university - those who have academic qualifications but have not met the admission requirements for language proficiency. Students need to pass the EAP program to transition to their disciplinary studies.

EAP, as "focused instruction informed by an understanding of texts and constraints of academic contexts," has been conceptualized and developed as a field since it emerged from English for Specific Purpose (ESP), a goaldirected program based on needs analyses of the learners (Hyland, 2006, p. 2). Because academic contexts are commonly associated with higher education, EAP students are often either studying or wishing to study in higher education where English is the medium of education. EAP programs thus differ from English as a Second Language (ESL) programs, which might be general language programs not associated with higher education. Although EAP programs vary in their pedagogical intentions because of participants' different levels of English proficiency and education, different disciplines, and different countries of origin or first languages, we believe that a review of the relevant research would highlight the importance of the present study by focusing on (a) the needs of students, (b) the efficacy of content-based instruction, and (c) the potential of learning transfer from EAP to disciplinary courses.

\section{Meeting Students' Needs}

Research has examined whether EAP programs fulfill students' needs in preparing them to meet the challenges of mainstream university for graduate studies (Terraschke \& Wahid, 2011), undergraduate studies (Cheng \& Fox, 2008; Evans \& Green, 2007; Tweedie \& Kim, 2015), or both gradu- 
ate and undergraduate studies (Dooey, 2010; Floyd, 2015; Fox, Cheng, \& Zumbo, 2014). For example, two studies explored post-EAP students' perceptions by interviewing them in their first university term in Australia (Dooey, 2010) and Canada (Tweedie \& Kim, 2015). The participants reported that although the EAP pathway program helped them develop academic skills such as writing, group work, and note taking, it did not help meet their needs in vocabulary and reading (Tweedie \& Kim, 2015) or the oral and listening proficiencies that they needed to integrate with local students and participate in class discussions (Dooey, 2010). Participants' desire for opportunities to interact with and learn from locals or previous EAP students, as Tweedie and Kim (2015) point out, highlights the importance of social acculturation. In contrast to the above complaints about the misalignment of EAP instruction with students' needs, positive comments from EAP students were reported by Fox et al. (2014). In their survey of 641 non-native English speaking (NNES) students in 36 language support programs (EAP or ESL) at 26 Canadian universities, Fox et al. found that English language programs supported the development of skills and strategies, which positively impacted the academic and social engagement of NNES students. However, the positive impact of the programs was moderated by levels of student anxiety, stress, and motivation. The study thus indicates that the programs should address these affective factors to increase the potential impact of language support.

To identify students' needs for an EAP program, Evans and Green (2007) conducted a survey among 5,000 undergraduates in a large Hong Kong English-medium university. Findings suggested that an EAP program was needed to help students develop subject-specialist vocabulary, express ideas in complex grammar, and make oral presentations in the content courses. Learning these academic skills, as Floyd (2015) notes based on an online questionnaire survey of both testing and EAP pathway students, is helpful to all international graduates and undergraduates, regardless of their level of language proficiency. Compared with their peers who entered the university directly by passing an English proficiency test, the EAP students in some Australian universities were found to express more confidence in their academic skills (Dyson, 2014; Floyd, 2015; Terraschke \& Wahid, 2011). For example, the EAP students in Terraschke and Wahid's (2011) interview study reported that they used more reading strategies, had a better idea of what was required of them in their courses, and were more satisfied with their progress in writing and content with their university experience as they transitioned to a graduate accounting program.

Different from the above studies that compared the experiences of EAP students with their non-EAP peers, Cheng and Fox (2008) interviewed three groups of EAP students to compare their perceptions of the role of EAP instruction at different stages of their study in three Canadian universities: 11 students who had already completed EAP courses and had moved on to their 
undergraduate courses, 37 students taking disciplinary courses concurrently with an EAP course, and 8 pre-university students currently taking only EAP courses. Compared to those in the disciplinary programs who appreciated in hindsight the skills that they had learned in the EAP courses, students who were taking the EAP program concurrently saw the courses as a "safe haven" providing social support (p. 326). In contrast, the majority of students enrolled in pre-university programs were impatient to move into disciplinary classes and therefore saw the EAP classes as a "barrier" (p. 325). The study suggests that students get a better sense of what they need while doing their disciplinary studies.

\section{Efficacy of Content-Based Instruction}

To better understand the needs of students and thus increase the relevance of the language instruction, some EAP programs have placed a greater focus on disciplinary content or implemented content-based instruction (CBI). Analyzing students' evaluations of the program, follow-up interviews with selected students, and a simulated final exam, Snow and Brinton (1988) found that students who had taken an intensive English presessional program linked to a content course at a U.S. university felt they were better readers and writers. With improved confidence, these students also performed in their disciplinary courses at the same level as their NNES peers who had not taken the EAP course because of their higher English proficiency scores. The positive and long-term effect of content-based language support has also been reported by Song (2006), involving first-semester students in an American college who were enrolled in either content-linked $(n=385)$ or non-content-linked $(n=385)$ ESL classes. In the content-linked program, the classroom activities and assignments were linked to the psychology courses that students were taking. Comparing students' academic records, Song found high achievement in many areas demonstrated by students enrolled in the content-linked ESL program, including better grades and greater likelihood of graduating, compared with those who received non-content-linked ESL instruction.

Positive effects have also been reported in a content-linked tutorial program for a first-year architecture course at the University of Melbourne (Baik \& Greig, 2009) and an EAP course for first-year engineering students at a Canadian university (James, 2006). The mixed-method study conducted by Baik and Greig (2009) included questionnaires completed by 37 students along with analysis of their academic performance after the program. The authors found that the attendance in this tutorial increased throughout the term, as students found it "relevant and useful" (p. 409). Similarly, James (2006) found that all five participants in his study in Canada were able to transfer learning from the CBI course to some or all of their disciplinary courses. Transfer of reading and writing skills were most commonly re- 
ported, including "synthesizing gist \& distinguishing units of discourse" and "using appropriate syntactic patterns, devices" (p. 795). Two of the factors that contributed to the success of the EAP program, as noted by James, were the use of similar content and level of challenge compared to the disciplinary courses. Together, these studies suggest that content-based instruction is effective if students in EAP courses are studying the same discipline. Because these students have already been admitted into university courses, the question remains how EAP instruction can help students with conditional admission to develop academic skills to be carried over to their content studies.

\section{Transfer of Writing Skills from EAP to Disciplinary Courses}

Research has also suggested that transfer of writing skills can occur if writing tasks for EAP pathway students closely match those in the target situation (Counsell, 2011; Leki \& Carson, 1994, 1997; Storch \& Tapper, 2009). In their much-referenced survey study, Leki and Carson (1994) reported that ESL or EAP undergraduates who had practiced academic writing skills (e.g., outlining, drafting, revising, and managing sources) were able to use the relevant skills to write their university assignments. However, students reported different writing experiences in the EAP programs where they practiced writing with a focus on personal experiences using source texts only as a springboard, compared with writing for disciplinary courses, where they were required to write from source texts to display knowledge. To further compare how ESL students write under each of these conditions, Leki and Carson (1997) then conducted an interview study involving both undergraduates and graduates. The student informants reported challenges demonstrating knowledge of content in disciplinary writing because they had had no practice with the types of source-based writing that they were expected to do in the content courses. The authors thus sent a strong message that EAP writing classes should help students practice text-responsible writing required in disciplinary classes.

Also focusing on the transfer of writing skills, Storch and Tapper (2009) examined the writing of 69 graduate international students enrolled in an EAP course at the beginning of their degree programs. Students were assigned a writing task that required them to draw on content knowledge by describing "an important issue or concept or process that is relevant to [their] field of study" (p. 210). Students completed the task in the first week and then again in the 10th week of term. The authors found that most students' writing improved linguistically and rhetorically over the semester in the EAP program. In contrast, when EAP graduates did not practice writing with disciplinary content, transfer of writing skills seemed to be limited (Counsell, 2011). Based on her questionnaire survey and a follow-up interview with four graduates in the Faculty of Business at an Australian university, Counsell 
noted that students were not able to recognize the generic writing strategies they learned from the EAP program and transfer them effectively and consistently to business-specific writing. The study suggests that EAP programs should offer students access to discipline-specific content to enable them to become familiar with their future disciplinary writing.

\section{The Present Study}

The above review of literature suggests that EAP programs do provide benefits for students who lack English language proficiency in the following contexts: when comparing the progress of EAP students with NNES students who did not take the EAP courses (Dyson, 2014; Floyd, 2015; Terraschke \& Wahid, 2011); when there is content-based instruction (Baik \& Greig, 2009; James, 2006; Snow \& Brinton, 1988; Song, 2006); and when writing tasks are connected to disciplinary content or resemble those in the disciplinary studies (Leki \& Carson, 1997; Storch \& Tapper, 2009). Research findings about EAP programs in other contexts, however, have been inconclusive. The programs can be either useful in helping students develop in certain skills but not others (Dooey, 2010; Tweedie \& Kim, 2015), or helpful in some students' eyes but not others (Cheng \& Fox, 2008). Previous research also suggests that "EAP program" is used as an umbrella term for different programs - that is, graduate or undergraduate programs, discipline- and faculty-specific programs (e.g., business, engineering), or a specific type of program open to students of different disciplines, educational levels, and language proficiency levels. As these contextual factors have a large impact on what is taught and how specific to student needs the instruction can be, there is a paucity of research to inform specific program areas or contexts. This draws our attention to the Canadian context, which is "underexamined" (Fox et al., 2014, p. 59). Of the four studies in this review that were conducted in Canada (Cheng \& Fox, 2008; Fox et al., 2014; James, 2006; Tweedie \& Kim, 2015), only two were conducted in the previous five years, a small number when considering that the number of ESL students entering Canadian universities is increasing at a rapid rate. In addition, none of these studies was designed to follow students from the EAP program to the disciplinary programs. Research is thus needed to identify how students view the impact of an EAP program on their performances in the disciplinary classes by following them from an EAP to the disciplinary programs in the Canadian context. To this end, we interviewed eight students in their eight-week EAP program and then during the first term of their disciplinary studies in a Canadian university to address the following questions:

1. How do students perceive their experiences in the EAP program?

2. To what extent do students perceive that the intensive EAP has contributed to their academic performance in the disciplinary programs? 


\section{Method}

\section{The EAP Program}

The English Language Centre (ELC) at the participating university was chosen for this research because the Academic Programmer at the ELC had expressed an interest in having research conducted on their EAP programs for students with conditional admission to the university degree programs. These students had met the university's academic entrance requirements except for English language proficiency. To be granted conditional admission, students must have achieved an average IELTS score of 6 (with no scores less than 5.5) or a minimum TOEFL score of 82. The ELC runs about eight sections of intensive EAP classes during the summer, which contain students of mixed disciplines. In the year in which the present data were collected, 91\% of the students (106 out of 116) were from Mainland China, the rest (10; 9\%) were from France, Iran, Japan, Korea, Kuwait, and Mexico. The classes are not streamed according to level as there is little variation in the language proficiency level of students entering the program.

Students in the eight-week EAP program take two integrated skills classes over the course of the program, which consists of two blocks of Reading and Writing (for a total of 3 hours and 20 minutes per day) and one block of Speaking and Listening (for 1 hour and 40 minutes per day). To move on to a degree program, students have to achieve $75 \%$ in both courses. Classes are held on Monday through Thursday, with optional workshops offered on Friday. Students in the EAP program are mostly undergraduates, with about half entering arts and the other half entering a variety of other disciplines in sciences or applied sciences.

\section{Participants}

At the end of the second week of the EAP program, students in two classes (15 in each class) were invited to participate in the study. One class consisted of students who were all from Mainland China, while the other had 4 from other countries (France, Japan, and Korea). Prior to the start of the study, all participants were given written descriptions of the intended research, and their informed consent was obtained in accordance with ethical procedures for research with human participants. Eight students volunteered. Two of them planned to study arts, and the rest would study sciences or applied sciences. The cultural backgrounds of the eight participants were fairly representative of the EAP classes; seven students came from China and one from South Korea (Table 1). Three of the students had studied at universities in China for two years and were transferring into their third year. Pseudonyms chosen by the participants are used in this report.

Jerry, originally from Korea, was the only student in this study who was not from China. However, he did not feel that having a large number of class- 
mates from one country was an issue. Jerry entered the program with a score of 87 on the TOEFL internet-based test, only slightly under the score for regular admission to the university, which he expressed some bitterness about. Jerry had experience living in a Spanish-speaking country where he attended an American school. He was entering his first year in the Faculty of Science.

Table 1

Summary of Participants' Profiles

\begin{tabular}{lccccl}
\hline & Age & Gender & Country & Field of study & Class status \\
\hline Lulu & 20 & F & China & Applied Science & 3rd year transfer student \\
Sara & 20 & F & China & Science & 3rd year transfer student \\
Anna & 20 & F & China & Arts & 3rd year transfer student \\
Sisi & 19 & F & China & Science & 1st year \\
Mason & 18 & M & China & Arts & 1st year \\
Amy & 19 & F & China & Science & 1st year \\
Bramwell & 18 & M & China & Science & 1st year \\
Jerry & 22 & M & Korea & Science & 1st year \\
\hline
\end{tabular}

Three of the eight students had already completed two years of undergraduate study in China and were transferring into second-year courses in the Canadian university to study computer engineering (Lulu), natural resource conservation (Sara), and computer science (Anna). Both Lulu and Anna chose Canada in particular because of family connections. Lulu, having studied English for 12 years, was an outgoing and confident English speaker who "love[d] speaking with friends." She was keen to meet people from other cultures and regularly watched American movies to practice listening. Sara had studied English for six years and hoped to improve her listening and writing skills in the EAP program. She was a very self-reliant student who depended on her own abilities to solve problems, while keeping a sense of humour and often joking about the challenges she faced. Of the three transfer students, Anna was the least confident about her English ability and was worried about being "the last one in the class." She felt that speaking was her weakest skill, although it was due to her IELTS writing score that she had to attend the EAP program.

Apart from Anna, Mason was the only other participant registered in the Faculty of Arts, studying modern languages (Spanish, German, Russian) and geography. Mason was outgoing and enjoyed speaking with native English speakers and using colloquial language. He had attended a Canadian offshore school in Beijing and was keen to discover more about Canadian culture and meet people from different language backgrounds. Of all the participants, Mason was the most impatient to begin his disciplinary courses. 
The remaining three participants were enrolled in the Faculty of Science, taking courses in environmental science (Sisi), land-food systems and nutrition and health (Amy), and math, economics, and physics (Bramwell). Sisi expected a lot from herself and, like Anna, was quite anxious about her ability to manage disciplinary courses in English. She chose to study in Canada because of its proximity to the United States, where she would like to travel. Unlike Sisi, Amy chose to study in Canada because a member of her family had previously studied here. She saw grammar as her weakest point and was looking forward to practicing her speaking skills. Amy, like Mason, had attended an international school in China. Amy felt that she had worked hard in her final year of high school and wanted to relax and not be too challenged by schoolwork. Differing from Sisi and Amy, Bramwell had a dream to attend this university. He was the only participant who was offered direct admission into another Canadian university, but chose to accept conditional admission to this one. Bramwell considered pronunciation his biggest weakness in English and looked forward to practicing English with EAP students from different countries.

\section{Data Collection and Analysis}

The first author, who is a native-English speaker with EAP teaching experience, conducted four interviews in English with each participant. The interviews were semistructured, and each lasted about 30 minutes to an hour. The interviews were friendly, casual, and with lots of clarifications and follow-up. Although English was not the participants' native language, they were able to express themselves in some depth and asked for questions to be rephrased or vocabulary to be explained when they were unsure about a question. The first two interviews were conducted while students were taking the EAP courses, and students were asked for biographical data and about their expectations/ experiences of the EAP program. The third and fourth interviews were conducted during participants' first university term, and students were asked about how the EAP program had benefitted them, the challenges they faced, and their recommendations to improve the program (see Appendix for interview questions). To thank the students for their participation, the first author offered one-on-one writing tutorials equal to the time spent in interviews. The participants said they appreciated the free tutorials and the opportunity to talk to a native-English speaker. We believed that the participants felt free to share their ideas with the first author because she was not associated with the EAP program or the departments of their disciplinary studies. With permission, the interviews were audio-recorded and later fully transcribed for all participants but one, who asked that notes be taken instead.

Analysis was conducted of each individual case and then across cases to determine if there were shared profiles and common themes (Auerbach \& Silverstein, 2003). The process started with the first author coding manually 
according to themes that emerged from the data, which were then tabulated to allow comparisons of different topics across profiles (Yin, 2013). Emerging themes included positive feedback about the EAP program and students' improved skills and increased confidence, as well as areas of concern as they anticipated their disciplinary courses. Themes concerning disciplinary courses include benefits of the EAP program such as practice making presentations and the opportunity to develop social relationships with classmates, as well as various challenges such as difficulties understanding lectures/classmates, completing writing tasks, adjusting to the Canadian educational system, and making new friends with their classmates. To check intercoder reliability, a TESL instructor with a graduate degree coded $10 \%$ of the data separately using the codes provided by the first author. The agreement was $90 \%$. Differences were resolved through discussion. We also conducted member check by providing a draft copy of findings to the participants. Two students responded with factual corrections of their biographies.

\section{Findings and Discussion}

\section{Students' Experiences in the EAP Program}

As they began the EAP program, most of the participants did not have a strong opinion about having to take an EAP course. However, Jerry felt some frustration at having to spend a lot of money just to study English, and Mason was glad that he could "get [the program] over with" in two months. Furthermore, Mason had few expectations of the program: "I don't expect to learn anything. I just want to pass." Despite their low expectations, Jerry and Mason, like all other participants, reported improvements in their English skills over the course of the eight weeks. Mason, in contrast to his initial response to the program as an obstacle to his university career, was very enthusiastic about the program: "I enjoyed the whole program -in and out of class." The participants found the EAP program especially helpful in developing their confidence in writing and speaking, though they also expressed anxiety about doing well when they moved to disciplinary studies (Table 2).

Increased confidence in writing. Several students commented at the end of the EAP program that the program had helped with their writing. "We wrote a lot of essays and it helped a lot," said Jerry. Similarly, Lulu said, "Before I came to this program I had no idea about essays because I think essays are really hard for me to write. But right now ... I know the rules of how to write it." Specifically, Anna said the class had benefitted from the feedback from the instructor. In her words:

ANNA: [The instructor] told us a lot of things about writing an essay and the format, grammar especially. Feedback about grammar is very ... careful. He gave everyone his opinion. 
Table 2

Overview of Participants' Comments on Their Experiences in the EAP Program

\begin{tabular}{lccc}
\hline & $\begin{array}{c}\text { Increased confidence } \\
\text { in writing }\end{array}$ & $\begin{array}{c}\text { Increased confidence } \\
\text { in speaking }\end{array}$ & Anxiety to do well \\
\hline Lulu & $\checkmark$ & $\checkmark$ & $\checkmark$ \\
Sara & $\checkmark$ & & $\checkmark$ \\
Anna & & & $\checkmark$ \\
Sisi & $\checkmark$ & $\checkmark$ & $\checkmark$ \\
Mason & & $\checkmark$ & $\checkmark$ \\
Amy & & $\checkmark$ & \\
Bramwell & $\checkmark$ & & \\
Jerry & & & \\
\hline
\end{tabular}

Like Anna, other participating students, who were highly motivated to improve their writing skills for regular university courses, also made reference to the usefulness of the detailed written feedback they received. It is clear that the instructors' feedback contributed to students' improvement in writing, a conclusion that Storch and Tapper (2009) also reached in their study.

Increased confidence in speaking. Participants also commented on their increased confidence in speaking as a result of the practice of group presentations and group discussions in the EAP program. Like EAP students in previous research (Dooey, 2010) who have also found class presentations help them build confidence, Bramwell and Lulu said:

BRAMWELL: [W] did speaking presentations ... to practice our pronunciation and the fluency in English.... I think it's quite essential skill for us to attend university so I think it's great.

LULU: There was a lot of group work-every day.... It's a lot of chances to work with each other ... because when you work with other people you know you have to express your opinion and tell other people your opinion, so it's ... a good way to force you to speak.

Amy said that she appreciated the feedback from the instructor on students' presentations:

AMY: Every session in the speaking class-every presentation-our teacher will give everyone ... feedback on what's the point you need to improve and what's the point that you did very well.

Reflecting on the speaking practices, Lulu said she benefitted from being exposed to this "Western culture" of teaching, which consists of mostly group work and student presentations. She believed that the EAP experience would 
help her adjust to the disciplinary courses: "Now I know how this education system works ... so I feel more comfortable." She expected that being exposed to EAP teachers would provide confidence "to get you through another teacher [in the regular university courses]." Like Lulu, Jerry acknowledged that going directly into university would have been really hard.

Anxiety to do well. While the majority of the students reported gains from practicing writing and speaking, some also expressed anxiety at the end of the EAP program around their general ability to do well in their university courses. For example, Sara, Sisi, and Anna wished that the EAP program could have helped them develop more subject-specialist vocabulary, a common concern among students in previous research (Counsell, 2011; Evans \& Green, 2007; Terraschke \& Wahid, 2011). In addition, some participants from China (Amy, Bramwell, Lulu, and Mason) wished that they had had more chances to practice English and that the EAP classes had not contained so many students from their own country. The Chinese participants reported speaking Mandarin mostly after class, as they felt uncomfortable speaking English with their Chinese peers. The present study confirms students' needs for a multicultural EAP class to better prepare them for university classes (Dooey, 2010). Their concerns to do well in the disciplinary studies led us to our exploration of their experiences in the first term of their university programs.

\section{Experiences in Disciplinary Studies}

As they moved to the university courses in the first term, participants reported difficulties in the disciplinary courses, which would have been more challenging had they not taken the EAP program. Their disciplinary challenges were in contrast to their experience in the EAP program, which they looked back on as mostly "fun" and relatively carefree. The challenges most reported in students' first university term included understanding lectures, completing writing tasks, adjusting to the Canadian education system, and seeking social/peer support (Table 3).

Understanding lectures. The one big challenge common to all eight participants was difficulty understanding lectures, a problem that has been reported in other studies of EAP programs (Dooey, 2010; Terraschke \& Wahid, 2011). The main difficulties were the professors' rate of speech and the presence of an accent (many students said that some of their professors were not native English speakers). Anna reported missing an assignment because she did not understand the professor when he assigned the homework orally in class. Sisi also got lost when the professor talked about politics and made references to the federal election. She explained:

SISI: There's a lot of stuff I don't understand. I need to read the [textbook]. And sometimes he will talk about politics and some parties in Canada and I really don't understand how many parties and what 
kind of party ... He even talks about American parties (laughs). It's difficult, although it's not on the exam.

Table 3

Overview of Participants' Comments on Their Challenges in Disciplinary Studies

\begin{tabular}{lcccc}
\hline & $\begin{array}{c}\text { Understanding } \\
\text { lectures }\end{array}$ & $\begin{array}{c}\text { Completing } \\
\text { writing tasks }\end{array}$ & $\begin{array}{c}\text { Adjusting to the } \\
\text { Canadian system }\end{array}$ & $\begin{array}{c}\text { Seeking social/peer } \\
\text { support }\end{array}$ \\
\hline Lulu & $\checkmark$ & & $\checkmark$ & $\checkmark$ \\
Sara & $\checkmark$ & $\checkmark$ & $\checkmark$ & $\checkmark$ \\
Anna & $\checkmark$ & $\checkmark$ & & $\checkmark$ \\
Sisi & $\checkmark$ & & $\checkmark$ & $\checkmark$ \\
Mason & $\checkmark$ & $\checkmark$ & $\checkmark$ & $\checkmark$ \\
Amy & $\checkmark$ & $\checkmark$ & & $\checkmark$ \\
Bramwell & $\checkmark$ & $\checkmark$ & & $\checkmark$ \\
Jerry & $\checkmark$ & & & $\checkmark$ \\
\hline
\end{tabular}

Sisi's comment confirms previous observations that students need not only the knowledge of course content to be able to participate in class discussions, but also "a knowledge of popular North American culture, a repertoire of newsworthy current events, and an ability to express a range of perspectives on social issues" (Duff, 2003, p. 120).

Jerry wished they had had more practice listening to colloquial English during the EAP program:

JERRY: [T] he [EAP instructors] ... speak really clearly and they speak really formally. So it wasn't really hard to understand. But you know ... Canadians don't use proper grammar and formal language [in everyday talk]. I think this kind of stuff is really important.

Jerry made an important point about not being exposed to natural speech. The implication is that students might be better prepared if the listening conditions in the EAP program were more similar to those in the disciplinary courses. In fact, a student in James's (2006) study was reported to benefit from having an EAP instructor who spoke quickly because, as he says, "no other instructor talks faster than him. He is the fastest. So that helps" (p. 799).

Like the student in James (2006), Anna and Lulu appreciated the listening practice they had in the EAP program, without which they thought the lectures would have been much harder to follow, as this observation from Lulu illustrates:

LULU: [The listening practice in the EAP program] helped a lot. I'm so grateful that I got into the EAP program because without those few months I [would have more problems]. 
Lulu and other students said that they benefitted from the EAP listening practice that included Canadian TV shows and online TED Talks. However, while TED Talks are similar to lectures in some respects, a lecture is usually not a polished performance that is wrapped up neatly in 20 minutes or less. The ways that students engage with these tasks are also different; in a class lecture, students are able to listen only once, whereas they have access to captions while watching a TED Talk online and can also watch it multiple times if needed. In other words, real lectures delivered naturally, as Flowerdew and Miller (1997) point out, are characterized by "messiness" (p. 44). This explains why students struggled to follow the lectures despite the practice in the EAP program.

Completing writing tasks. Another challenge for the participants was the disciplinary writing assignments, which differed from the assignments in the EAP program in terms of type, length, and complexity. Although Jerry, Sisi, and Lulu did very little writing (e.g., lab reports) in their science and engineering courses, Bramwell, Mason, Amy, and Anna all took an English course and were required to write a research term paper, a writing task that they had not done before. The research papers, as Anna said, were much longer (about 2,000 words) than anything they had been assigned (about 500 words) in the EAP program. Bramwell said he had to email his professor and TA many times just to get feedback on the appropriateness of a topic on which he could write 2,000 words. Bramwell's experience suggests that EAP instructors could have introduced different assignments from university professors and talked about how to approach the tasks by finding academically acceptable resources and narrowing the topic to make it workable.

Apart from research papers, essay writing was another task that challenged Sara and Mason. Although essay writing was the most commonly mentioned writing assignment in the EAP program, it is, as Sara said, very different from writing an essay in a specific discipline. To write an essay in her conservation course, Sara said she needed to include "specific" content based on "a lot of understanding" and "many readings." Although the EAP courses helped improve her writing skills, Sara was challenged with the requirement of content in her disciplinary essay:

SARA: I think [the EAP lessons] did help. I will always think about what the EAP teacher told me ... "Don't use ...," etc., little tips I always can remember. But for the [content] idea, no.

Sara's comment suggests that the essay task in the EAP program differs from the essay assignment in her conservation course, which needs to demonstrate her understanding of source readings. Essay writing is often the most common genre practiced in ESL courses (Johns, 1997). However, the demand for source-based disciplinary writing suggests that the essay genre is not all-encompassing, and teaching one generic "academic English" to prepare students may lead them to think "they simply have to master a set of rules 
which can be transferred across fields" (Hyland, 2002, p. 392). As most EAP programs need to cater to students from different disciplines, they need to either raise students' awareness of disciplinary differences in essay writing or expose them to typical essays of their chosen discipline. Of course, this can only be done if time permits and if there is homogeneity in the study interests of the students. There is an obvious advantage of an ESP as opposed to a generic EAP approach.

Adjusting to the Canadian education system. A third challenge that students reported concerned difficulties adjusting to the Canadian educational system. In other words, students were struggling because the demands and expectations were not what they were used to. This was especially true for Sara and Lulu, who were transferring from Chinese universities. After taking disciplinary courses for two months, Lulu concluded that the EAP courses were more similar to the "Chinese way of teaching" rather than what she was experiencing in the disciplinary classes. She explained:

LULU: In China, the teacher ... will tell you how this works and you go home and do the assignment. But here all the things [the instructor] said in the lecture you have to [apply] it [yourself]. I'm still getting used to this way. Here the instructor will prefer you to learn by yourself ... but I'm the kind of person used to doing what the teacher said.... I don't know how to systematically learn by myself. I have to change myself maybe to fit into this study system.

In the above comment, Lulu described how she learned by being guided with specific instructions in both her Chinese university and the Canadian EAP program. Her reliance on the instructors put her in jeopardy when she was suddenly expected to learn autonomously by disciplinary professors at the Canadian university. Like Lulu, Sara also struggled to understand what the professors were looking for in the essays she was assigned in her conservation classes. She compared her experiences of writing in China and in her current program in Canada:

SARA: In my country I have to write essays, it has a format.... I have to do another way [here]. It's uncomfortable for me.... I feel I was stuck in some place, like I don't know where I was wrong ... And sometimes the teacher just give you what you should write in the essay and I thought I understood, but ... during the writing, I still get confused.... In China our points [in the essay always follow] the government ... policy ... The way I think in China affect me a lot.

Sara was uncomfortable writing in the Canadian university because she was not told specifically what she can or cannot write. This is because she was used to writing in China, where she was explicitly instructed to align her views with those of the Chinese government. For Sara, writing a paper in Canada differed from how she wrote and viewed writing in China. 
As transfer students, both Sara and Lulu stated that the expectations of the Canadian university were different from the schools they had attended for two years in China. Sara said she thought the Canadian university was "strict" and when asked to explain, she said (laughing), "Like you have to do every homework." She commented on expectations in universities in China compared to Canada:

SARA: In Chinese university, it's a loose atmosphere, so suddenly I have to [move] from a "freedom university" to a "strict university." And it's a little bit challenge.

Lulu had the same experiences as Sara in her first term. Lulu said that she usually did not do homework in her home university but managed to pass the exam by reviewing the course work before the exam. She believed that she could do the same in Canada but was lost in her first class at the Canadian university. She felt stupid because she had not done the prereading assignment like the other students:

LULU: In the first lecture a lot of students would ask questions but I didn't know where the questions came from! They came from nowhere! I didn't know the terms. I didn't know where they got the questions! It was on [the website]. I saw that but I didn't know it was SO important, you know. I just thought maybe you could read it in your spare time or something. I didn't know that it would affect your [understanding of] lecture or something. Right now I know! So stupid!

One feels sorry that Lulu thinks she was stupid; it is quite a cultural adjustment. The importance of prereading highlights the value of teaching content in an EAP class where students can read about a topic, then listen to a lecture or documentary, and then ask and answer questions or write about the topic.

Compared with Lulu's and Sara's challenges adjusting to expectations, Mason and Amy said that their transition to the Canadian education system would have been harder without the EAP courses. They talked about how they benefitted from practicing oral presentations in the EAP program. In the first term of their disciplinary classes, Mason did a presentation in his English class and Amy did so in both her biology and English classes. Both Amy and Mason had positive experiences, and Mason received one of his highest marks for that assignment. They said that to manage these presentations they relied on what they learned in the EAP program. For example, Amy credited making presentations in the EAP program for helping students to "overcome our nerves." Similarly, Lulu said:

LULU: If I didn't enter this [EAP] program ... I [wouldn't] have experience with anything like presentations or essays ... but right now I know how this education system works, how they want you to give 
[presentations], so I think I feel more comfortable with that... I won't feel panic before a presentation.

Seeking social/peer support. By the midpoint of the fall term, all participants reported some difficulty making new friends in their disciplinary programs. Unlike some international students who deliberately chose not to pursue friendships with local students (Myles \& Cheng, 2003), all eight of the participants in this study were interested in meeting students from other language and cultural backgrounds but found various obstacles. Participants reported a lack of opportunities and time because of busy lives on the part of domestic students. Amy described her difficulties in making friends with her classmates:

AMY: In the first week I tried to make new friends, such as native speakers... I found it was a little difficult because we don't have too much common to talk about and we just have class together two or three times a week. No time for us to talk too much.... We just say "Hi" and "Nice to meet you" and that's it. Everyone is very busy, they don't have time to talk to you too much.

Lack of language proficiency also contributed to the challenge of making new friends. Amy felt it was hard to make herself understood because she was in a class with many native-English speakers and no other Mandarin speakers. She explained:

AMY: Actually until now all of my classmates I meet in Bio and English are all English-speaking.... It's helpful, but it's a little difficult. Because sometimes I cannot talk to them very fluently, so maybe there is some difficulty for us to talk.

Frustrated with her ability to communicate well in English, Amy was feeling somewhat isolated although she was exposed to more English with many English-speaking classmates. She recalled an incident early in the term when she started to lose confidence in her speaking ability. The incident took place in a class when she tried to ask the instructor a question, but he was not able to understand her. The instructor then asked her to print out her question, which she found very embarrassing. Similarly, Jerry reported that he sometimes did not understand his classmates when they asked him about either the course content or nonacademic topics. As Sara said, "Sometimes you just don't know how to say it in English." Bramwell and Lulu believed that the lack of English proficiency affected their ability to make friends. Lulu commented:

LULU: Yeah. (hesitates) When you are in a new country, your language is a problem - people will prefer to talk to somebody who has the same language as them. Right now if you say something with a word I don't understand, it's difficult for me.... When I talk 
with them and ask a question sometimes they don't have patience, because, you know, for engineering, this program is super hard and everyone's got a lot of work to do and so they don't have time to explain to you.

Although the lack of English proficiency kept participants from establishing friendships with local classmates, the participants remained optimistic that in time they would be able to make friends. Meanwhile, all of the participants kept up friendships with their classmates from the EAP program; some of them saw each other only occasionally because they were in different faculties and residences, but others remained close friends. The participants were thankful for the EAP program, which helped form a community for social and peer support in their university studies. The following quotes illustrate that participants were glad that they had taken the EAP program:

AMY: Yeah, until now all of my friends are from the summer [EAP] program. I really appreciate that I could take the EAP program. I met so many nice people there. My friends all come from the EAP program and we always go out together.

BRAMWELL: By taking the [EAP] program I met lots of people. So that's the most important part, I think. Like your friends help you get into the new environment.

Sara also said that she was starting to build a network through her friends from the EAP program:

SARA: Mostly it's related to my friends I met in the [EAP] program.

We have the same courses and I just meet someone who says, "I know so-and-so" and I say, "Oh, I know him too." It's like a snowball. "Do you have a friend studying in CONS 200? Okay I will introduce you."

As the above remarks indicate, the EAP program played an important role in assisting students to establish a social network and make friends with other students, which helped them adapt to their university studies. Whether the friends are conationals, other NNES students, or domestic native speakers, students benefit from all of these relationships (Zappa-Hollman \& Duff, 2015). By maintaining strong friendships with the classmates they met in the EAP program, the participants felt less isolated when they entered their disciplinary courses.

\section{Summary and Recommendations}

The findings of this study support previous research conducted on this topic - that EAP programs are useful and help students in their subsequent disciplinary studies (e.g., Cheng \& Fox, 2008; Fox et al., 2014; Tweedie \& 
Kim, 2015). The students in this study reported that the EAP program provided them with improved language proficiency and academic strategies, especially in writing and speaking, which helped them feel more confident as they entered their university courses. Apart from helping students develop academically, the participating Canadian EAP program also allowed students to build a network of peers whom they depended on for academic and social support after the program. The participants, however, wished that the program could have provided more opportunities for them to meet people from other cultures. The high percentage of Chinese students in the present program suggests that attracting many Chinese students to Canada may create a challenge to have classes with students from multiple cultures. The lack of exposure to students from other cultures might have contributed to the students' later difficulty in interacting with other students, including Englishspeaking classmates, when they entered their disciplinary courses. Together with Tweedie and Kim (2015), the present findings stress the importance of social acculturation in EAP instruction.

The students also faced a number of challenges in their disciplinary courses, which, as the students noted, would have been more serious if they had not taken the EAP program. All eight students struggled to understand lectures as a result of the professors' rate of speech and cultural references and, in many cases, an accent that was unfamiliar to them. Some students also felt that their lack of listening skills and idiomatic language impeded their ability to communicate with their native speaker classmates. In addition, they struggled with the new and more complex tasks that they faced in disciplinary courses, such as the 2,000-word research term paper. Although the science students did less writing compared with arts students, the former faced similar writing challenges in their English 100-level courses. The challenges, as Leki and Carson (1997) have pointed out, concern the types of source-based writing to demonstrate understanding of disciplinary content knowledge. In addition, some students were surprised to find that they were expected to read or learn class content on their own prior to class. This was especially true for two students who were transferring from universities in China, because they had already experienced university life and had certain expectations about what it entailed. With the involvement of transferring students, which is common in the present program in Canada, the study suggests that special attention should be paid to help these students adjust to the Canadian context.

Readers need to be aware of the limitations of the study. First, participants were interviewed not in their first language and, therefore, might be hindered in their full ability to express their meanings. Second, the eight students might not represent the student population. The fact that they volunteered to be interviewed suggests that they are more motivated than others. Third, we are aware that interviews are a social practice when the first author, as the interviewer, is participating in co-constructing the accounts (Talmy, 2010). In 
other words, her background as an EAP instructor might have some power or influence that shaped participants' comments. Fourth, the present arts and science participants reported similar challenges in their first university term. To identify disciplinary differences, we might need to follow these students in their second term or even the second year when they have taken more disciplinary courses. Finally, the present interview data could have been triangulated with the perspectives of the EAP and disciplinary instructors, as well as analyses of students' writing samples. Future study needs to explore the issue with rich and thick description.

The present findings suggest that the process for international students to fully engage with a new university is slow and evolving. The present general EAP program is constrained by its eight-week time frame and its mandate to teach to a wide variety of disciplinary backgrounds. One should not assume that language skills can be taught in isolation and must be in place in order to do disciplinary studies (Zamel, 2004), nor should one believe that one can safely predict which genre or content will be most beneficial for EAP students (Spack, 2004). It is a difficult task for EAP instructors to work against these constraints and wrong assumptions. We present three recommendations to help students transition into disciplinary courses.

First, because students had few opportunities to interact with international students from other countries or domestic English-speaking students, it is recommended that the EAP program include more organized social activities to encourage students to mix with those from other cultures, including Canadians. Second, the challenges that students faced in understanding lectures and classmates in their first term of their disciplinary courses might be mitigated by the use of relevant materials and tasks that are similar to those in the target situation. For example, students could practice listening to real lectures, either live or recorded, that include a variety of accents. In order to implement this, instructors or course designers would need to observe disciplinary classes, have discussions with professors, or interview former students to understand what is required of students once they leave the EAP program. An alternative is to ask students to go out and survey university students in their field on a topic of their own interest, including exams, courses, assignments, and so on. The third recommendation relates to the finding that students were unprepared for certain demands of their courses, especially the expectation of independent learning. The EAP program should prepare students for these demands by, first, discussing in class the demand for independent learning and what that means in terms of professors' expectations, and, second, fostering independence by asking students to be responsible for their own learning, perhaps by assigning tasks similar to those expected of them in disciplinary courses. For students who are transferring from a foreign university, it would be especially helpful to discuss the expectations of the university. 
We checked the online information of EAP programs of several Canadian universities and found some program descriptions that correspond to the recommendations we are making. For example, in the Bridge to Academic Success program in the University of Waterloo, upper-year students fill the role of peer leaders to provide student support. The university also organizes conversation circles for EAP students to meet with native English-speaking students, as well as "Meet and Greet" sessions where EAP students meet and socialize with upper-year students from their faculty. Similarly, two other universities provide either a study centre where EAP students can speak with Canadian volunteers (the University of Victoria) or social activities for students from different countries to share ideas and opinions (the University of Toronto). With regards to preparation for disciplinary studies, the EAP program for graduate students at York University offers an academic communications course for students to explore concepts and language related to their disciplines. Students at the University of Winnipeg can take a course to practice note-taking for lectures. In addition, EAP students at the University of Waterloo are assigned to interview a professor to learn about academic culture and university conventions. Future studies need to explore these programs to identify how they meet the needs of students. Canada is an important country to do this research because of its receptivity to immigrants and visa students, as well as its variety of university programs and program outcomes. In addition, research needs to also involve native-English speaking first-year students who may lack academic literacy and are likely to either drop out or take a break from studies (Fox, Haggerty \& Artemeva, 2017). To identify "the best means of support" to all students in need, an important step for universities is to implement a postentry diagnostic assessment procedure (Fox et al., p. 53).

\section{Acknowledgements}

This article is based on the first author's MA research, which won the best MA thesis in the Department of Language and Literacy Education at University of British Columbia. We thank the participating students and the anonymous reviewers for their valuable comments on an earlier draft.

\section{The Authors}

Karin Keefe is a Vancouver-based writer and ESL instructor. Her interests include EAP curriculum and academic test prep. She has an MA in TESL from the University of British Columbia.

Ling Shi is a professor in the Department of Language and Literacy at the University of British Columbia. Her research focuses on second language writing, and she has published in journals such as Applied Linguistics, Research in the Teaching of English, and TESOL Quarterly.

\section{References}

Auerbach, C., \& Silverstein, L. B. (2003). Qualitative data: An introduction to coding and analysis. New York, NY: New York University Press. 
Baik, C., \& Greig, J. (2009). Improving the academic outcomes of undergraduate ESL students: The case for discipline-based academic skills programs. Higher Education Research \& Development, 28(4), 401-416. http://doi.org/10.1080/07294360903067005

Cheng, L., \& Fox, J. (2008). Towards a better understanding of academic acculturation: Second language students in Canadian universities. Canadian Modern Language Review, 65, 307-333. http://doi.org/10.3138/cmlr.65.2.307

Counsell, J. (2011). How effectively and consistently do international postgraduate students apply the writing strategies they have been taught in a generic skills-based course to their subsequent discipline-based studies? Journal of Academic Language and Learning, 5(1), A1A17. Retrieved from http://journal.aall.org.au/index.php/jall/article/view/80/100

Dooey, P. (2010). Students' perspectives of an EAP pathway program. Journal of English for Academic Purposes, 9, 184-197. http://doi.org/10.1016/j.jeap.2010.02.013

Duff, P. A. (2003). Intertextuality and hybrid discourses: The infusion of pop culture in educational discourse. Linguistics and Education, 14, 231-276. http://doi.org/10.1016/j.linged.2004.02.005

Dyson, B. P. (2014). Are onshore pathway students prepared for effective university participation? A case study of an international postgraduate cohort. Journal of Academic Language and Learning, 8, A28-A42. Retrieved from http://journal.aall.org.au/index.php/jall/article/ view/294/196

Evans, S., \& Green, C. (2007). Why EAP is necessary: A survey of Hong Kong tertiary students. Journal of English for Academic Purposes, 6, 3-17. http://doi.org/10.1016/j.jeap.2006.11.005

Flowerdew, J., \& Miller, L. (1997). The teaching of academic listening comprehension and the question of authenticity. English for Specific Purposes, 16(1), 27-46. http://doi.org/10.1016/ S0889-4906(96)00030-0

Floyd, C. B. (2015). Closing the gap: International student pathways, academic performance and academic acculturation. Journal of Academic Language and Learning, 9(2), A1-A18. Retrieved from http://journal.aall.org.au/index.php/jall/article/view/336/220

Fox, J., Cheng, L., \& Zumbo, B. D. (2014). Do they make a difference? The impact of English language programs on second language students in Canadian universities. TESOL Quarterly, 48, 57-85. http://doi.org/10.1002/tesq.103

Fox, J., Haggerty, J., \& Artemeva, N. (2017). Mitigating risk: The impact of a diagnostic assessment procedure on the first-year experience in engineering. In J. Read (Ed.), Post-admission language assessment of university students (pp. 43-65). Cham, Switzerland: Springer International.

Hyland, K. (2002). Specificity revisited: How far should we go now? English for Specific Purposes, 21, 385-395. http://doi.org/10.1016/S0889-4906(01)00028-X

Hyland, K. (2006). English for academic purposes: An advanced resource book. London, UK: Routledge.

James, M. A. (2006). Transfer of learning from a university content-based EAP course. TESOL Quarterly, 40, 783-806. http://doi.org/10.2307/40264308

Johns, A. M. (1997). Text, role and context: Developing academic literacies. Cambridge, UK: Cambridge University Press.

Leki, I., \& Carson, J. G. (1994). Students' perceptions of EAP writing instruction and writing needs across the disciplines. TESOL Quarterly, 28, 81-101. http://doi.org/10.2307/3587199

Leki, I., \& Carson, J. (1997). "Completely different worlds": EAP and the writing experiences of ESL students in university courses. TESOL Quarterly, 31, 39-69. http://doi.org/10.2307/3587974

Myles, J., \& Cheng, L. (2003). The social and cultural life of non-native English-speaking international graduate students at a Canadian university. Journal of English for Academic Purposes, 2, 247-263. http://doi.org/10.1016/S1475-1585(03)00028-6

Snow, M. A., \& Brinton, D. M. (1988). Content-based language instruction: Investigating the effectiveness of the adjunct model. TESOL Quarterly, 22, 553-574. http://doi.org/10.2307/3587256

Song, B. (2006). Content-based ESL instruction: Long-term effects and outcomes. English for Specific Purposes, 25, 420-437. http://doi.org/10.1016/j.esp.2005.09.002

Spack, R. (2004). The acquisition of academic literacy in a second language: A longitudical case study, updated. In V. Zamel \& R. Spack (Eds.), Crossing the curriculum: Multilingual learners in college classrooms (pp. 19-45). Hillsdale, NJ: Lawrence Erlbaum Associates. 
Storch, N., \& Tapper, J. (2009). The impact of an EAP course on postgraduate writing. Journal of English for Academic Purposes, 8, 207-223. http://doi.org/10.1016/j.jeap.2009.03.001

Talmy, S. (2010). Qualitative interviews in applied linguistics: From research instrument to social practice. Annual Review of Applied Linguistics, 30, 128-148. http://doi.org/10.1017/ S0267190510000085

Terraschke, A., \& Wahid, R. (2011). The impact of EAP study on the academic experiences of international postgraduate students in Australia. Journal of English for Academic Purposes, 10, 173-182. http://doi.org/10.1016/j.jeap.2011.05.003

Tweedie, M. G., \& Kim, M. (2015). EAP curriculum alignment and social acculturation: Student perceptions. (TESL Canada Journal), 41-57. http://doi.org/http://dx.doi.org/10.18806/tesl. v33i1.1226

Yin, R. K. (2013). Case study research: Design and methods (5th ed.). Los Angeles, CA: Sage.

Zamel, V. (2004). Strangers in Academia: The experience of faculty and ESOL students across the curriculum. In V. Zamel \& R. Spack (Eds.), Crossing the curriculum: Multilingual learners in college classrooms (pp. 3-17). Hillsdale, NJ: Lawrence Erlbaum Associates.

Zappa-Hollman, S., \& Duff, P. A. (2015). Academic English socialization through individual networks of practice. TESOL Quarterly, 49, 333-368. http://doi.org/10.1002/tesq.188

\section{Appendix. Interview Guide}

A. Questions for the first interview at the start of the EAP program

1 . What is your first language? What other languages do you speak?

2. How old are you? How long have you been in Canada?

3. How many years have you studied English? What would you like to improve in your English?

4. What are you planning to study in Canada? Have you already studied at the university level?

5. What do you expect to learn during this EAP program?

B. Questions for the second interview at the end of the EAP program

1. Did you think the EAP program was useful or not?

2. What problems have you had in your courses?

3. Have you had feedback from your teachers or classmates that has been helpful?

4. Did you work together with other students?

5. What suggestions do you have for improving the EAP program?

C. Questions for the third interview at midpoint of the first university term

1. What challenges have you experienced, particularly at the beginning of term?

2. Have you noticed any connections between things you learned in your EAP course and your disciplinary courses?

3. What are the similarities/differences in the assignments? 
D. Questions for the fourth interview at the end of the first university term

1. What skills are required in your university courses that you feel you have not learned well enough?

2. Did you spend time with students from your classes?

3. Looking back on the EAP program after completing your first term, do you think the EAP program was useful? Any recommendations? 